Savunma Bilimleri Dergisi

The Journal of Defense Sciences

Mayıs/May 2019, Cilt/Volume 18, Sayı/Issue 1.

ISSN (Bas1l1) : 1303-6831 ISSN (Online): 2148-1776

\title{
Çok Kültürlü İş Ortamlarında Entegrasyon Mekanizmaları: Uluslararası Barış Güçleri Üzerine Nitel Bir Araştırma*
}

\author{
Cem ŞEN**
}

$\ddot{O} z$

Bu çalışmanın amacı, uluslararası barış gücü görevlerinde başarılı olmak için kullanılmasının faydalı olabileceği kültürlerarası entegrasyon mekanizmalarının incelenmesidir. Barış gücü operasyonları, kültür temelli problemler potansiyeli taşımaktadır. Söz konusu problemlerin önlenmesi maksadiyla kültüre, kültürler arası ilişkilere ve bunların etkilerine bütünsel bir yaklaşım gelişstirmek gerekmektedir. Araştırma kapsamında; bu operasyonlara katılmıs asker ve sivil personel ile yapılan 49 mülakat, yazarın katılıml gözlemleri, rapor ve haberleri içeren arşiv araştırmasından elde edilen veriler değerlendirilmiştir. Nitel araştırma yöntemleriyle elde edilen bulgulara göre; etkin ve etkili bir yönetim kültürü oluşturabilmek için kültürel farklılıkları tolere edip onlara sayg göstermenin ve hibrid bir kültür oluşturmanın gerektiği ön plana çıktı̆̆l görülmüştür.

Anahtar Kelimeler: Çok Kültürlülük, Kültürel Farklllıklar, Kültürlerarası Entegrasyon Mekanizmaları, Kültürlerarası Yönetim, Uluslararası Barış Gücü Görevleri.

\footnotetext{
Bu çalışma 25.Ulusal Yönetim ve Organizasyon Kongresi, 25-27 Mayıs 2017, Ankara, Türkiye'de sunulmuştur.

** Dr., Millî Savunma Bakanlığı, cem.sen@ hotmail.com

Geliş Tarihi/Received:03.06.2018

Kabul Tarihi/Accepted:06.11.2018

Araştırma Makalesi/Research Article
} 


\title{
Integration Mechanisms in Multicultural Workplaces: A Qualitative Research on International Peacekeeping Operations
}

\begin{abstract}
The purpose of the study is to examine the intercultural integration mechanisms that can be used to be successful at international peacekeeping operations. Peacekeeping operations have potential for culture-based problems. In order to prevent such problems, it is necessary to develop a holistic approach to culture, cross-cultural relations, and their effects. In the scope of the research; 49 interviews with soldiers and civilian personnel who served in international peacekeeping operations, participant observations of the author, archive reviews including reports and media news were evaluated. According to the findings obtained by qualitative research methods; it has been seen that to create an effective and efficient culture of management it is required to respect and tolerate the cultural differences and create a hybrid culture.
\end{abstract}

Keywords: Multiculturalism, Cultural Diversity, Intercultural Integration Mechanisms,Cross-Cultural Management, International Peacekeeping Operations.

\section{Giriş}

1945-1990 yılları arasında yaşanan Soğuk Savaşın ardından başta Avrupa ülkeleri olmak üzere pek çok ülke savunma bütçelerinde kısıntıya gitmek ve mevcut askerî güçlerini azaltmak zorunda kalmıştır (Duffey, 2007; Soeters ve Tresch, 2010). Bunun sonucunda meydana gelen uluslararası kriz ve gelişmelerde; özellikle çatışan grupları barışa zorlama, aralarında tampon bölge oluşturma, ateşkes antlaşmasının izlenmesi, güvenliğin sağlanması ve istikrarın korunması, insani yardım gibi operasyonlarda (Rubinstein, 1993; Allen ve Yuen, 2014); kendi başına yeterli kaynaklara sahip olmayan ülkeler, diğer ülkeler ile birlikte hareket etmek ve kaynaklarını Uluslararası Barış Gücü (UBG) altında birleştirmek zorunda kalmıştır.

Etkili UBG operasyonları, çabaların birleştirilmesi ve belirli bir amaca yönlendirilmesini gerektirmektedir. UBG operasyonları, kendisini oluşturan ülkelerin gerek asker, gerekse de sivil aktörlerini, müdahalenin yapıldığı (ev sahibi) 
Çok Kültürlü İş Ortamlarında Entegrasyon Mekanizmaları:

ülkedeki yerel halk ile karşı karşıya getirmekte ve meydana gelen etkileşimden kaynaklanan kültür tabanlı problemlere yol açabilmektedir. Anılan aktörler; kişisel ve kurumsal çok değişik geçmiş ve kültürlerden gelen, değişik büyüklük ve çaptaki askerî birlikleri, hükümet dışı organizasyonları ve çok uluslu sivil kuruluşları içermektedir (Rubinstein, 1993). Aktörler büyüteç altına alındığında, yalnızca maddi unsurları ile değil, kültürel olarak da operasyon bölgelerine taşındıkları (Sığrı ve Topçu, 2012) ve yanlarında getirdikleri kendi kültürlerini, diğer ülkelerden gelen çalışma arkadaşlarına ve yerel halka yansıttıkları (Pouligny, 1999) gözlemlenebilmektedir. Bu açıdan bakıldığında katılımcı ülkelerin kültürlerinin bir araya gelmesinden oluşan çok kültürlü bir yapılanmanın söz konusu olduğu rahatlıkla tespit edilebilmektedir. Söz konusu çok kültürlülük ve doğal sonucu olan kültürel farklılıklar (Leca ve Vrânceanu, 2014), UBG’nün etkililiğini büyük oranda etkilemektedir. Bu nedenle anılan hassas konu, hem akademiklerin hem de UBG görevlerine katılanların dikkatini çekmektedir (Elron, Halevy, Ben-Ari ve Shamir, 2003).

Yerli yazında UBG görevlerinde kültürlerarası farklılıklarının çok sık ele alınıp incelendiğine rastlanmakla birlikte, kültürlerarası entegrasyon konusuna genellikle yabancı yazında rast gelinmekte, yerli yazında ise yeterince ele alınmadığı göze çarpmaktadır. Bu bağlamda çalışmada, öncelikle kültür kavramı üzerinde odaklanılacak; kültürlerarası farklılıklar ve kültürlerarası yönetim irdelenecek; Türk ulusal kültürü ve Türk askerî kültürü, Hofstede'nin altı boyutu kapsamında incelenecek; UBG görevlerinin icra edildiği koşullar ve söz konusu görevleri yerine getirirken karşılaşılan problemleri çözmek için yararlı olabilecek birtakım kültürlerarası bütünleştirme mekanizmaları UBG görevlerinde bulunan asker ve sivil personel ile yapılan mülakatlar, yazarın katılımlı gözlemleri, görev sonuç raporları ve haberlerini içeren arşiv araştırmasından elde edilen veriler bağlamında ortaya konulmaya çalışılacaktır.

\section{Kültür Kavramı, Kültürlerarası Yönetim ve Kültürlerarası Farklılıklar}

Hofstede, kültürü "zihinsel programlama", "aklın yazılımı" olarak tanımlamakta; anılan yazılımın insanlara küçük yaşlardan itibaren belirli bir toplumsal çevre içerisinde kodlandığını ve bunun bir sonucu olarak duygu, düşünce ve davranışların oluştuğunu vurgulamaktadır (Hofstede, Hofstede ve Minkov, 2010). Adler, kültürü; bir sosyal grubun tümü ya da çoğunluğu tarafindan 
paylaşılan, grubun yaşlılarınca genç jenerasyona aktarılmaya çalışılan, kişinin dünyayı algılamasını yapılandıran ve davranışlarını şekillendiren bir şey olarak ifade etmektedir (Adler, 1986, 1991).

Kültür, toplumları birbirinden ayıran en önemli özelliktir (Solomon ve Schell, 2009), bir nevi toplumların parmak izi gibidir. İnsana dair her şeyi ifade eden kültürün, toplumdan topluma değişiklik gösterdiği gözden kaçırılmamalıdır. Birbirinden farklı kültürel ortamlar, değişik davranışlara değişik anlamlar yüklemekte; aynı davranış, farklı ortamlarda farklı anlamlar ifade edebilmektedir (Klein, Pongonis ve Klein, 2000; Soeters, Van den Berg, Varoğlu ve Sığrı, 2006). Söz konusu farkl11ıklar, ancak o kültürün gözünden, içeriden bakılarak daha kolay anlaş1labilmektedir (Smith, Trompenaars ve Dugan, 1995).

Kültürlerarası yönetim bağlamında; kültürlerarası farklılıkların yaşandığı ortamlarda yöneticilerin hedeflenen etkinlik ve etkililiğe başarı ile ulaşabilmesi için öncelikle çok kültürlülüğün tanımlanması, avantaj ve dezavantajlarının ortaya konulması, çok uluslu örgüt yöneticisinin yerel yöneticilerin sahip olduğu özelliklerine ek olarak uluslararası çalışma ortamının gerektirdiği yeteneklere de sahip olması gerekmektedir (Adler, 1983). Bunun için çalışma ortamındaki kültürel farklı1ıkların göreve ve örgütün başarısına değer kattığı gerçeğinin (Joplin ve Daus, 1997; Soeters ve Tresch, 2010) ve kültürlerarası çalışma yeteneğinin bilincinde olunması gerekmektedir. Kültürlerarası çalışma yeteneği, bireylerin çok kültürlü ortamlara hızlı bir şekilde adapte olmasını sağlayan bilgi, yetenek ve motivasyondur (Selmeski, 2007).

Bir ülke için çok önemli anlamlar taşıyan kültür, o ülkenin askerî gücü için de önemli bir kavramdır. Çünkü tüm askerî kurumlar öncelikle içerisinde yaşadıkları kendi toplumsal kültürlerinin ve akabinde de üniversal askerî kültürün bir parçası olarak varlığını sürdürmektedir (Sığrı ve Topçu, 2012). Evrensel askerî değerleri içeren bir kültür (Elron, Shamir ve Ben-Ari,1999) mevcut olmakla beraber, tipik olarak ordular, mensubu oldukları ulusların birer parçasıdır ve onları ulusal kültürlerinden ayırmak, soyutlamak çok zordur.

UBG'lerinde görev alan ülkeler, operasyon alanına kendi ulusal kültürlerini de beraberlerinde getirdiklerinden; diğer ülkelerle aralarındaki kültürlerarası farklılıklardan kaynaklanabilecek zorluk ve çatışmalara hazırlıklı olunması gerekmektedir. Çünkü ülkeler; harekât alanına getirdikleri farklı dil, değer, norm ve davranışları, yetenek, eğitim, doktrin ve tecrübeleri ile önemli problem ve sürtüşmelere yol açabilmektedir (Elron vd.,1999). Söz konusu problem 
Çok Kültürlü İş Ortamlarında Entegrasyon Mekanizmaları:

Uluslararası Barış Güçleri Üzerine Nitel Bir Araştırma

ve sürtüşmelerin ana nedeni olarak; ötekileştirme, diğerlerinin ayrıştırılması, kültürel anlamda kendini daha üstün görme, beniçinci yaklaşım, iletişim ve koordinasyon problemleri ile denetim sorunları olarak gözükmektedir (Sı̆̆rı ve Topçu, 2012). Sargut'a (2010) göre kültür, temelde bütüncül özellikler sergilemekte, ancak bu çaba evrensel kültür düzeyine çıkıldığında önemli engeller ile karşılaşmaktadır. İşte tam da burada anılan problemlerin önlenebilmesi, engellerin aşılması, hiç değilse etkilerinin azaltılabilmesi için alınması gereken önlemlerin ortaya konulması gerekmektedir. Ancak örgütlenmenin ve yönetimin en iyi yolu olmadığı (Trompenaars ve Hampden-Turner, 1998: 2) gibi kültürel farklılıkların minimize edilmesi ve kültürlerarası entegrasyon mekanizmaları (Elron vd., 1999; Van Driel, 2011) için icat edilmiş reçete şeklinde bir formül de bulunmamaktadir.

\section{Uluslararası BG Görevleri ve Askerî Harekâtın Doğasından Kaynaklanan Koşullar}

Uluslararası BG'nde görev olan ülkelerin ordularının harekât alanına getirdikleri farklı kültürleri ile sahada önemli problem ve sürtüşmelere yol açabileceğini yukarıda vurgulamıştık. Söz konusu problemler, askerî faaliyetlerin doğasından kaynaklanan birtakım özellikler nedeniyle daha yoğun olarak yaşanabilmektedir, bunlar Elron ve arkadaşları (1999) tarafından;

- Görev ve operasyon alanında şartların tehlikeli ve belirsiz oluşu,

- Emir komuta bağlantısının hem ulusal ve hem de çok uluslu kuvvet olmak üzere iki başlı olması,

- Çok uluslu kuvvetlerin ihtiyaç üzerine acil bir şekilde ve kısa sürede bir araya toplanmas1, oluşturulması,

- Çok uluslu askerî gücün geçici bir süre ve geçici bir yapıda

- Klasik olarak bireysel görev süresinin genellikle altı ay ile kısitlı olması nedeniyle, bireyler arası güvenin tesisi ve koordinasyon gibi hususların zorlaşması olarak ifade edilmiştir.

Her ne kadar farklı farklı ülkelerden gelseler de askerî kuvvetlerin, evrensel ve kurumsal bir askerî kültürü paylaştıkları ve bünyelerinde birtakım bütünleştirme koşullarını taşıdıkları vurgulanabilir. Söz konusu koşullar; yapısal 
benzerlikler, standart prosedürler, sıkı kurallar ve güçlü bir hiyerarşi, barış ve uluslararası hukukun üstünlüğünün sağlanmasını içeren evrensel ulvi değerler, görev yapılan ülkede evinden uzak ve yabancı olunmasından kaynaklanan şartların birleştirici etkisi ile kültürel farklılıklara karşı artan tolerans seviyesidir.

Bir sonraki bölümde uluslararası görevlerin bütünleştirme koşulları içerisinde nasıl bir yol izleyeceği merak edilen Türk Ulusal Kültürü ve Türk Askerî Kültürü, Hofstede'nin altı boyutu perspektifinden irdelenecektir.

\section{Türk Ulusal Kültürü ve Türk Askerî Kültürünün Hofstede'nin Altı Boyutu Kapsamında İncelenmesi}

Kültürlerarası farklılıklar, değişik kültürlerde yaşayan insanların benzer konu ya da olaylar karşısında farklı düşünme, farklı değerlendirme, farklı kavrama ve farklı davranmalarına neden olmaktadır (Sargut, 2010). Kültürlerarası farkl111kları inceleyen Hofstede, dört boyut ortaya koymuştur, bunlar; belirsizlikten kaçınma, güç mesafesi, bireycilik-toplulukçuluk, erillik-dişillik'tir (Hofstede, Pedersen ve Hofstede, 2002). Müteakip çalışmalar (Michael Bond'un Çin Değerleri Anketi, Ronald Inglehart'nn Dünya Değerleri Anketi) sonucunda, söz konusu dört boyuta uzun-kısa vadeye odaklılık ile hoşgörü-baskıcı tavır boyutları eklenmiştir (Hofstede vd., 2010). Bir ülkenin ulusal kültürü çok çeşitli açı ve boyutlardan incelenebilmekle birlikte, bu makalede Türk ulusal ve askerî kültürü, Hofstede'nin kültürel boyutları temel alınarak irdelenecektir.

\section{Güç Mesafesi}

Bir kültürdeki bireylerin kurum ve örgütlerde gücün eşit olmayan bir şekilde dağılımını kabul etme derecesi olarak tanımlanabilmektedir (Hofstede vd., 2010). Yüksek güç mesafesi büyük güç ve servet eşitsizliklerinin olduğu ve buna müsamaha edildiği, düşük güç mesafesi ise firsat eşitliğine, bireyin güç ve zenginlik farklarına önem vermediği anlamına gelmektedir. Yüksek güç mesafesinin olduğu toplumlarda hiyerarşinin atlanması başkaldırı ve itaatsizlik olarak algılanırken, düşük güç mesafesinin olduğu toplumlarda insanların karar verme süreçlerine katıldıklarına ve görevin yerine getirilmesi için üstün atlanmasına s1klıkla rastlanılmaktadır (Adler, 1991).

Türk ulusal kültürü, güç mesafesi boyutu indeksinde yüksek derecede güç mesafesine sahip olan ülkeler arasında yer almıştır (Hofstede vd., 2010). Türk 
Çok Kültürlü İş Ortamlarında Entegrasyon Mekanizmaları:

Uluslararası Barış Güçleri Üzerine Nitel Bir Araştırma

askerî kültüründe de yöneticiler, genellikle yüksek güç mesafesi eğilimi göstermekte; bu kapsamda merkezi karar verme ve hiyerarşi önemli bir yer tutmakta, statü sembolleri sürekli olarak vurgulanmakta, üstlerin astlar hakkındaki düşüncesi önemli sayılmakta, astların üstlerine mutlak itaati söz konusu olmakta, üstlerle iletişim kurma ve ulaşma güçlügü yaşanmaktadır (Sığrı, 2006; Sığrı ve Topçu, 2012). Özellikle yapılan mülakatlarda Türk birliklerinin hangi ülkenin emir komutasına girerse girsin, birçok konuda son kararın o bölgedeki en kıdemli Türk komutana danışılmadan alınmadığı ifade edilmektedir. Türk askerî kültürünün, Türk ulusal kültürü gibi yüksek seviyede güç mesafesine sahip olma örneği sergilediği ifade edilebilir. Uluslararası BG görevlerinde yer alan diğer ülkelerin farklı seviyede güç mesafesine sahip olmaları, emir komuta birliğini oldukça önemseyen Türk askerî kültürünü olumsuz yönde etkileyebilmektedir. Bu durum, görevin başarı ile yerine getirilebilmesi için Türk askerî kültürünün uluslararası çalışma koşulları altında sergileyeceği güç mesafesi seviyesinde birtakım ayarlamalar yapmasına ihtiyaç doğurmaktadır.

\section{Belirsizlikten Kaçınma}

Bir kültürün bireylerinin, bilinmeyen ve belirsiz durumlar karşısında kendilerini tehdit altında hissetme derecesi olarak tanımlanabilmektedir (Hofstede vd., 2010). Bireyler kendilerini söz konusu durumlardan iş garantisi sağlayarak, birtakım biçimsel kural ve prosedürler getirerek, farklı düşünce ve davranışları dışlayarak, kabul edilmiş kesin doğrular ile uzmanların belirttiği durumların gerçekleşme ihtimalini kabullenerek uzak tutarlar (Adler, 1991). Belirsizlikten kaçınmanın yüksek olduğu toplumlarda, bireyler belirsizlikten endişe duymakta ve hayatı kendileri için daha güvenli ve garantili bir duruma getirmek amacıyla iş güvencesini, biçimsel kural ve prosedürlerle artırmaya çalışmakta; düşük olduğu toplumlarda ise bireyler belirsizliği daha kolay kabul etmekte ve riski göze almakta, yenilikler, değişiklikler ve farklılıklar karşısında daha hazır bir duruş sergilemektedirler (Hofstede vd., 2010).

Türk ulusal kültürü, belirsizlikten kaçınma boyutu indeksinde yüksek belirsizlikten kaçınmanın olduğu ülkeler arasında yer almıştır (Hofstede vd., 2010). Askerî ortamların çoğunlukla bünyesinde barındırdığı dinamik ve sürekli değişen belirsiz durumlar karşısında kapsamlı planlama yapılmakta, kurallara uyma desteklenmekte (Sı̆grı, 2006), aykırı fikirler bastırılmakta ve yeni fikirlere direnme 
söz konusu olmaktadır. Bu tür davranışlar, alınan vazifenin başarıyla yerine getirilmesinde yaratıcılığı ve inisiyatifi engellemek suretiyle başarısızlığa yol açabilmektedir. Ancak, askerî liderler yine de birçok şeyi önceden ayrıntılı bir şekilde planlamayı tercih etmekte, hiçbir şeyi şansa bırakmamakta; benzer şekilde Türk askerî kültüründe de liderin öngörüsü ve mesleki tecrübesi ile problemlere çare bulucu bir tavırla belirsizlik içeren şartları azaltması beklenmektedir (Sığrı ve Topçu, 2012). Türk askerî kültürünün, Türk ulusal kültürü gibi yüksek belirsizlikten kaçınma örneği sergilediğini ifade etmek yanlış olmayacaktır. Ancak, söz konusu durum uluslararası BG görevlerinde farklı belirsizlikten kaçınma derecesi gösteren ülkeler arasında bir takım zorluklar yaşanmasına sebebiyet verebilmektedir. Türk askerî personelince geleneksel olarak uygulanan yaklaşımlar yerine, takınılacak tavır ve sergilenecek uyumlu ve uzlaşmacı yaklaşımlar zorlukların aşılmasında katkı sağlayabilecektir.

\section{Bireycilik ve Toplulukçuluk}

Bireycilik, bireylerin bir grubun üyeleri olmaktan çok kendi başlarına hareket ettikleri, kendilerini ön planda tuttukları, bireylerin yalnızca kendileri ile çok yakın akrabalarından sorumlu oldukları yaklaşımı ifade etmekte; toplulukçuluk ise, toplumsal ilişkilerin çok daha yoğun bir şekilde yaşandığı ve kişilerin akrabalık, etnisite ve örgütsel ilişkiler nedeniyle diğer kişi ve gruplardan kendilerini ayırmaları ile öne çıkmaktadır (Hofstede vd., 2010). Bireyciliğin ön plana çıktığı toplumlarda kişiler arasındaki ilişkiler zayıftır, her bireyin kendi yönelimleri ve çıkarları doğrultusunda davranması beklenirken; toplulukçu yapıda ise, bireyler arasındaki ilişkiler güçlüdür ve toplumun çıkarları bireylerin çıkarlarından önce gelmesi beklenmektedir. Bireyselci kültürlerde toplum, bireyleri içsel baskı ile suçluluk duygusuyla; toplulukçu kültürlerde ise toplum, bireyleri dışsal sosyal baskı ile utanma duygusuyla kontrol altında tutmaktadır (Adler, 1991).

Türk ulusal kültürü, bireycilik-toplulukçuluk boyut indeksinde belirgin seviyede toplulukçu ülkeler arasında yer almıştır (Hofstede vd., 2010). Söz konusu özellik, Türk askerî kültürüne üniformasıyla bütünleşen askerin mensubu olduğu gruba ve hedeflerine bağl1lı̆̆ , benden ziyade biz vurgusunu öne çıkartması, çeşitli durumlar karşısında gözünü kırpmadan gönüllü olarak fedakârlık yapabilmesi (Soeters vd., 2007; Varoğlu ve Bıçaksız, 2005) ile yansımaktadır. Moral durumunu 
Çok Kültürlü İş Ortamlarında Entegrasyon Mekanizmaları:

Uluslararası Barış Güçleri Üzerine Nitel Bir Araştırma

yükselten uyum ve aynı fikirlerin paylaşılmasına olan vurgu, askerî liderlerin birlik ruhunu zorlanmadan oluşturmasına hizmet edebilmektedir. Grubun sahip olduğu değerlere aykırı davranmak veya karşı gelmek, toplulukçu özellik gösteren Türk kültüründe affedilmesi çok zor bir hata sayılabilmektedir (Sı̆grı, 2006). Fikir birliği ve uyumlu olma, herhangi bir gruba üye olabilmenin ana faktörleridir; gruplar da kendi üyelerini koruyup kollamakta ve karş1lı̆ında ise üyelerinden sadakat beklemektedir. Örgütsel ortak amaç ve hedeflere sahip olunması, disiplin ve biçimsel kurallar, örgütsel normlara uyulması yönünde yadsınamayacak derecede etkiye sahiptir (Sığrı ve Topçu, 2012). Ancak, toplulukçuluğun özellikle iştirak edilecek uluslararası görevlerde, yenilikçiliği ve yaratıcılığı engellemesi ihtimaline (Sargut, 2010) karşı gerekli tedbirler alınmalıdır.

\section{Erillik ve Dişillik}

Erillik para, itibar ve güç kazanma, ataklık/saldırganlık ve kontrol gibi değerlerin; dişillik ise bireylerarası ilişkiler, diğer insanlar için duyulan kaygılar ve yaşam kalitesi gibi değerlerin toplumda baskın olma derecesidir (Adler, 1991; Hofstede vd., 2010). Eril kutupta yer alan insanlar erkek ve kadınların eşit olmadığını savunan, daha çok başarı, rekabet, güçlü olma gibi erkeklere özgü olduğu vurgulanan değerlerin yüksek olduğu; dişil kutupta yer alanların ise erkek ve kadınlar arasında çok az fark gördüğü, yaşam kalitesi, çevrenin korunması, sıcak ilişkiler, işbirliği ve uzlaşma, ihtiyaç sahiplerine yardım, iş güvencesi ve affedicilik gibi kadınlara has değerlere önem verilmesi ile ilgilidir (Adler, 1991).

Türk ulusal kültürü, erillik-dişillik boyutu indeksinde kısmi seviyede dişil özellik sergileyen ülkeler arasında yer almıştır (Hofstede vd., 2010). Türk askerî kültürü, Türk ulusal kültürü gibi topluma ve toplumun değerlerine duyarlı olma, maddi unsurlara değer vermeme, vatan, bayrak, şeref ve kahramanlık gibi kavramları yüceltme, sezgileri önemseme, fikir birliğini sağlamaya çalışma, astların sorunlarıyla ilgilenme hasletleri ile öne çıkmaktadır. Liderlerin astlarını yetiştirme ve bunu yaparken de alçakgönüllülüğü ve diğer birç̧ok olumlu yönleriyle onlara örnek olmaları kısmen dişil özellik göstermelerini teyit etmektedir. Söz konusu dişil kültüre has özellikler ortalamayı norm olarak kabullenme, yavaş ve küçük değişim süreci, maddesel başarı ve ilerlemenin kabul edilmemesi, kişileri kayırma ve olumsuzlukları örtbas etme gibi olumsuz davranışları (Sığrı ve Topçu, 2012) da içermektedir. Bahse konu hususların uluslararası barış gücü görevlerinde 
özellikle eril nitelik gösteren ülke silahlı kuvvetleriyle sürtüşmelere neden olabileceği gözardı edilmemelidir. Uzlaşma kültürünün yaratacağı sıcak atmosfer içerisinde eril ve dişil özelliklerin olumlu yönlerinin ön plana çıkarılmaya çalışılmasının, doğabilecek sürtüşmeleri azaltabileceği ifade edilebilir.

\section{Uzun Vadeye Odaklıık ve Kısa Vadeye Odaklılık}

Uzun vadeye dönük toplumlarda insanlar geleceğe bakarlar, tutumlu olmaya, tasarruf yapmaya ve sabırlı olmaya önem verirler; kısa vadeye dönük toplumlarda insanlar şimdiki zamana ve geçmişin erdemlerine, geleneklere, sosyal statüye önem atfeder (Hofstede vd., 2010) ve hemen sonuç almaya yönelirler (Altay, 2004). Uzun döneme yönelik kültür; değişime açık, dinamik, geleceğe odaklanmış ve daha geniş bir görüş açısına sahiptir, bu bağlamda çocukların yetiştirilmesi büyük öneme sahiptir. Kısa döneme yönelik kültür ise durağan bir özellik sergileyip, sosyal kodlara uymayı gerektirmektedir; ancak kısa vadeli yönelim miyopik kararlar almaya yol açabilmektedir (Hofstede vd., 2010).

Türk ulusal kültürü, uzun vadeye odakl111k indeksinde kısa vadeye odaklı ülkeler arasında yer almıştır (Hofstede vd., 2010). Türk ulusal kültürü gibi Türk askerî kültürü de kısa vadeye odaklı bir özellik sergilemekte; statik bir yapı içerisinde cari işlerin süratle görülmesi, sonuçların çabuk alınmasına çalışılması, geçmişten gelen ve büyük öneme sahip geleneklere sayg1 gösterilmesi, sosyal statüye önem atfedilmesi gibi özellikler taşımaktadır. Bu bağlamda, uzun vadeye odaklı ülke silahlı kuvvetleriyle icra edilen uluslararası barış gücü görevlerinde üst düzey amacın belirlenmesi ve amaca ulaşmak için izlenecek yolların tespit edilmesinde problemlere yol açabilmektedir.

\section{Hoşgörü ve Baskıcı Tavır}

Hoşgörü, yaşamdan zevk almak ve eğlenmekle ilgili doğal ve temel insan dürtülerinin göreceli tatminlerine izin veren, pozitif yaklaşımı benimseyen bir toplumu ifade ederken; baskıcı tavır ise, sıkı sosyal normlar vasıtasıyla ihtiyaçların tatminini kısıtlayan ve onları organize eden, eleştirel yaklaşımı benimseyen bir toplumu ifade etmektedir (Hofstede vd., 2010). Amerikan menşeli antropoloji çalışmalarında yer alan gevşek ve sıkı toplum ayrımını çağrıştırmaktadır; gevşek toplumlarda belirli norm ve davranışlardan sapmalar daha kolay tolere edilirken, 
Çok Kültürlü İş Ortamlarında Entegrasyon Mekanizmaları:

Uluslararası Barış Güçleri Üzerine Nitel Bir Araştırma

s1k1 toplumlar grubun değerlerine güçlü bir şekilde bağl1, biçimsel, statik ve dayanışmacı bir tavır sergilemektedir (Hofstede vd., 2002).

Türk ulusal kültürü, hoşgörü-baskııı tavır indeksinde kısmen baskıcı tavır sergileyen ülkeler arasında yer almıştır (Hofstede vd., 2010). Türk ulusal kültürü gibi Türk askerî kültürü de sıkı normlar yoluyla ihtiyaçların tatminini sınırlayan ve onları düzenleyen, belirli norm ve değerler bağlamında kısmen baskıcı bir özellik sergilemektedir. Her faaliyetin kontrol altında bulundurulmaya çalışılması, bu maksatla detaylı planlamaların yapılması, önceliğin her şeyden önce görevin başarılmasına odaklanılması da kısmen baskıcı tavrın bir özelliği olarak ortaya çıkmaktadır.

Uluslararası BG görevlerinin icra edildiği koşullar; yüksek güç mesafesi, yüksek belirsizlikten kaçınma, toplulukçu, kısmen dişil, kısa vadeye odaklı ve kısmen baskıcı tavır eğilimi gösteren Türk askerî kültürünü, değişik şekillerde etkileyebileceği vurgulanabilir. Özellikle görev verilirken açık ve net olması, emir komuta birliği, bir başka ifade ile tek başlı yapının varlığı gibi Türk askerî kültürünün tercih ettiği yöntem ve uygulamalar, çok uluslu kuvvette görev alınması durumunda birtakım problemlere yol açabilmektedir. Çünkü farklı kültürel yapılara sahip ülke askerî kültürleri, Hofstede'nin ortaya koyduğu boyutlar bağlamında Türk askerî kültürüne taban tabana zıt yaklaşımlar sergileyebilmekte ve söz konusu çok kültürlü yapı çeşitli anlaşmazlık ve sürtüşmelere neden olabilmektedir. Meydana gelen problemlerin aşılması için mevcut koşulların irdelenerek esnek bir yapı içerisinde bu koşullar üzerine inşa edilecek bütünleştirme mekanizmalarının kullanılabileceği ifade edilebilir.

\section{Araştırma ve Bulgular}

\section{Katılımclar}

Araştırmada 2005-2016 yılları arasında Kosova, Bosna-Hersek, Lübnan ve Afganistan'da icra edilen BG operasyonlarında görev yapmış 32 askerî, 9 Birleşmiş Milletler (BM) ve 8 de Avrupa Güvenlik ve İşbirliği Teşkilatı (AGİT) mensubu toplam 49 personel ile yapılandırılmış mülakatlar gerçekleştirilmiş, yazarın katılımcı gözlemleri ile UBG operasyonlarında görev yapmış personelin hazırladığı ve Türkiye'de bağlı oldukları kurumlara sundukları 71 adet görev sonuç raporu ile 2005-2016 tarihleri arasında gazete, televizyon ve internet örün 
sayfalarında yayımlanan toplam 347 haberi içeren arşiv analizinden faydalanılmıştır. Katılımcıların demografik bilgileri Tablo 1'de sunulmuştur.

Tablo 1. Kat1lımcıların Demografik Bilgileri

\begin{tabular}{|l|l|c|c|}
\hline \multicolumn{2}{|c|}{ Demografik Özellik } & N & Yüzde (\%) \\
\hline \multirow{2}{*}{ Cinsiyet } & Erkek & 37 & 75,5 \\
\cline { 2 - 4 } & Kadın & 12 & 24,5 \\
\hline \multirow{2}{*}{ Medeni Durum } & Evli & 32 & 65,3 \\
\cline { 2 - 4 } & Bekâr & 17 & 34,7 \\
\hline \multirow{4}{*}{ Eğitim Düzeyi } & Lisans & 49 & 100 \\
\cline { 2 - 4 } & Lisansüstü & 41 & 83,6 \\
\hline \multirow{5}{*}{ Kaş Aralığı } & $25-30$ & 7 & 14,3 \\
\cline { 2 - 4 } & $31-35$ & 14 & 28,5 \\
\cline { 2 - 4 } & $36-40$ & 12 & 24,5 \\
\cline { 2 - 4 } & $41-45$ & 9 & 18,4 \\
\cline { 2 - 4 } & $46-50$ & 7 & 14,3 \\
\hline \multirow{3}{*}{ Görev Süresi } & $1-10$ & 32 & 18,3 \\
\cline { 2 - 4 } & $11-20$ & 24 & 65,5 \\
\cline { 2 - 4 } & $21-35$ & 11 & 22,4 \\
\hline & 6 Ay ve Daha Az & 14 & 28,7 \\
\cline { 2 - 4 } & $6-12$ Ay & & \\
\cline { 2 - 4 } & 12 Ay'dan Fazla & & 16,2 \\
\hline
\end{tabular}

Yapılan içerik analizleri ile nitel verilere ulaşılmıştır. İçerik analizi; mülakat, gözlem, sonuç raporları ile arşiv analizlerinden elde edilen verilerin kodlanması (kendi içinde anlamlı bir bütün oluşturan belirli bir kavram altında toplanması), sonrasında kodlardan yola çıkarak belli başlıklar altında toplanan kategorilerin incelenmesi ile yapılır ve temel amacı metinlerde nesnelliği sağlamak ve okuyan herkesin aynı şeyi anlamasını sağlamaktır (Sığrı, 2018).

\section{Araştırma Sorusu ve Kullanılan Ölçüm Araçları}

$\mathrm{Bu}$ çalışmada araştırma sorusu "Uluslararası BG görevlerinde başarılı olmak için kullanılmasının faydalı olabileceği kültürlerarası entegrasyon 
Çok Kültürlü İş Ortamlarında Entegrasyon Mekanizmaları:

Uluslararası Barış Güçleri Üzerine Nitel Bir Araştırma

mekanizmaları nelerdir?" şeklinde oluşturulmuştur. Mülakatlarda BG operasyonlarında görev almış personele yöneltilen ve içerik analizi yöntemiyle değerlendirilen sorular şunlardır:

- Uluslararası BG görevlerinde ne tür kültürel problemler ile karşılaştınız?

- Karşılaştı̆ıııız problemleri aşmak ve görevinizde başarılı olmak için kullandığınız bütünleştirme mekanizmaları ya da yöntemleri nelerdir?

- Kullandığınız yöntemlerde işbirliği ve uzlaşmanın rolü oldu mu?

- Kullandığınız yöntemler işe yaradı mı? Ne kadar etkiliydi? Ne kadar sürede sonuç verdi? Örnek verebilir misiniz?

- Kullandığınız yöntemler önyargı ve kalıp düşüncelerden kurtulmuş, kendine has kural, norm, değer, davranış ve paylaşılan amaçları içeren hibrid bir kültür oluşturulmasına yardımcı oldu mu?

Verilerin içerik analizi QDA Miner 4.0 nitel veri analizi yazılımı ile yapılarak elde edilmiştir. Bu kapsamda en çok vurgulanan hususlar olarak iletişim, iyi niyet, ortak amaç ve değerler, bilgi paylaşımı ve koordinasyon, takım ruhu, kültürel farklılıklar, farklılıklara tolerans ve saygı, sonuç odaklılık ve ortak kültür oluşturma şeklinde tespit edilmiştir. Elde edilen verilerin analizi ile oluşturulan kod ve kategoriler Tablo 2'de sunulmuştur.

Tablo 2. Kod ve Kategoriler

\begin{tabular}{|c|c|c|c|c|}
\hline Kategoriler & Kodlar & $\mathbf{N}$ & $\begin{array}{c}\text { Tekrarlanma } \\
\text { Sıklığı }\end{array}$ & $\begin{array}{l}\text { Tekrarlanma } \\
\text { Yüzdesi (\%) }\end{array}$ \\
\hline \multirow{5}{*}{ Problemler } & İletişim & \multirow{5}{*}{49} & 44 & 89,8 \\
\hline & Farklı Kültürler & & 42 & 85,7 \\
\hline & Belirsizlik & & 42 & 85,7 \\
\hline & Tecrübesizlik & & 39 & 79,5 \\
\hline & K1sa Görev Süresi & & 28 & 57,1 \\
\hline \multirow{5}{*}{$\begin{array}{l}\text { Entegrasyon } \\
\text { Mekanizmaları }\end{array}$} & Görev Öncesi Eğitim ve & \multirow{5}{*}{49} & 42 & 85,7 \\
\hline & Görev Paylaşımı & & 39 & 79,5 \\
\hline & Bilgi Akışı ve Koordinasyon & & 41 & 83,6 \\
\hline & Takım Ruhu Oluşturma & & 40 & 81,6 \\
\hline & Görev Sirasında Ortak & & 46 & 93,9 \\
\hline
\end{tabular}




\begin{tabular}{|c|c|c|c|c|}
\hline Kategoriler & Kodlar & $\mathbf{N}$ & $\begin{array}{c}\text { Tekrarlanma } \\
\text { Sıklığı }\end{array}$ & $\begin{array}{l}\text { Tekrarlanma } \\
\text { Yüzdesi (\%) }\end{array}$ \\
\hline \multirow{4}{*}{$\begin{array}{l}\text { İşbirliği ve } \\
\text { Uzlaşma }\end{array}$} & İyi Niyetli İletişim & \multirow{4}{*}{49} & 44 & 89,8 \\
\hline & Kişisel Yetenek ve Ehliyet & & 37 & 75,5 \\
\hline & İşbirliği ve Tecrübe Paylaşımı & & 42 & 85,7 \\
\hline & Tartışma ve Çözüm Üretme & & 36 & 73,5 \\
\hline \multirow{5}{*}{ Başarı } & Eğitim & \multirow{5}{*}{49} & 42 & 85,7 \\
\hline & Kişisel Yetenekler & & 35 & 71,4 \\
\hline & Örgütsel Yetenekler & & 38 & 77,5 \\
\hline & Ortak Amaç & & 42 & 85,7 \\
\hline & Sonuç Odaklılık & & 41 & 83,6 \\
\hline \multirow{5}{*}{$\begin{array}{l}\text { Çözüm } \\
\text { Yolları }\end{array}$} & Kültürel Farkındalık & \multirow{5}{*}{49} & 44 & 89,8 \\
\hline & Farkl11ıklara Tolerans ve & & 41 & 83,6 \\
\hline & Farkl111kların & & 43 & 87,7 \\
\hline & Ortak Amaç ve Değerler & & 42 & 85,7 \\
\hline & Takım Ruhu ve Hibrid Kültür & & 44 & 89,8 \\
\hline
\end{tabular}

Mülakatlardan elde edilen nitel verilerin yazarın katılımcı gözlemleri, görev sonuç raporları ve 2005-2016 tarihleri arasında gazete, televizyon ve internet örün sayfalarında yayımlanan haberleri içeren arşiv analizi ile toplanan nitel verilerin desteklenip desteklenmediği araştırılmış; araştırma süresince konunun uzmanları ile görüş alışverişinde bulunulmuştur. $\mathrm{Bu}$ bağlamda, araştırmanın geçerlilik ve güvenilirliği sağlanmaya çalışılmıştır. Yukarıdaki yöntemler incelendiğinde; çalışmanın sınırlı sayıda personele ulaşması, nitel veri toplama yöntemlerinin yanında nicel veri toplama yöntemlerinden faydalanılmaması, bu çalışmanın kısıtları olarak ortaya çıkmaktadır.

\section{Bulgular}

Çalışma kapsamında mülakatlarda sorulan sorulara verilen cevaplar incelendiğinde, kültürel farklılıkların bilincinde olunduğu ve söz konusu farklılıkların yönetilmesi gerektiği konusunda fikir birliğine sahip olunduğu göze çarpmaktadır. Özellikle belirli bir amacın gerçekleştirilmesi için bir araya getirilmiş görev gücünün etkililik ve etkinlik seviyesinin artırılması maksadıyla 
Çok Kültürlü İş Ortamlarında Entegrasyon Mekanizmaları:

Uluslararası Barış Güçleri Üzerine Nitel Bir Araştırma

birtakım mekanizmalara ihtiyaç duyulduğu, çabaların birleştirilmesi ve belirlenmiş amaca yönlendirilmesi gerektiği hususları birçok katılımcı $(\% 85,7)$ tarafından vurgulanmıştır.

Yüksek güç mesafesi ve yüksek belirsizlikten kaçınma özellikleri gösteren Türk askerî kültürünün; görev verilirken açık ve net olması, emir komuta birliği, bir başka ifade ile tek başlı yapının varlığı gibi tercih edilen yöntem ve uygulamalar, çok uluslu kuvvette görev alınması durumunda birtakım problemlere yol açabilmektedir. Çünkü farklı kültürel yapılara sahip ülke askerî kültürleri, Türk askerî kültürüne tamamen zıt yaklaşımlar sergileyebilmekte ve söz konusu çok kültürlü yapı çeşitli anlaşmazlık ve sürtüşmelere neden olabilmektedir. Örneğin katılımcılardan biri tarafindan verilen olay incelendiğinde; Kosova'da birlik komutanı olarak yabancı ülke askerinin emir komutasında olan lider, verilen emirleri uygulamadan önce mutlaka millî olarak bağlı olduğu kıdemli komutanın onayını almaya çalışmıştır. Söz konusu sürecin uzaması ve yabancı komutanın ise ivedi olarak emrin yerine getirilmesini talep etmesi Türk birlik komutanını strese sokmuştur. Türk birlik komutanı, hem millî hem de BG görevi şapkası altında ifa etmesi gereken görevi, millî karar sürecini inisiyatif kullanma alanlarını belirleyip kısaltarak, işbirliği ve uzlaşma yoluyla çözümleyebilmiştir. Meydana gelen problemlerin aşılması için mevcut koşulların irdelenerek esnek bir yapı içerisinde bu koşullar üzerine inşa edilecek bütünleştirme mekanizmalarının kullanılabileceği ifade edilmiştir.

Türk millî kültürü gibi toplulukçu bir özellik sergileyen Türk askerî kültürü, Bosna-Hersek (EUFOR) görevi esnasında görev alan tüm ülkeleri aynı amaca yönelmiş olarak algılamış, iyi niyetle Hristiyan ülke mensupları için önemli olduğunu düşündüğü Noel tatili boyunca tüm görevleri üstlenmiş, diğer ülkelerin personelinin tatil için harekât alanından ayrılmalarına olanak sağlamıştır. Ancak ne varki Noel tatilinden kısa bir süre sonra Müslüman ülke mensuplarının dini bayramı için tatil yapma isteği çok uluslu karargâhta görevli komuta kademesince reddedilmiştir. Benzer kapsamda Noel'in tatil olarak kabul edilmesine karşıllk diğer bir kültürün dini bayramının tatil olarak kabul edilmemesi durumuna bir anlam verilememiştir. Durum bu çifte standart kapsamında gündeme getirilerek yapılan müzakereler sonucunda hem Türklerin hem de Müslüman yerel halktan EUFOR bünyesinde çalışanlar için bayram tatili yapmalarına izin alınmıştır. 
Burada daha önce gösterilmiş işbirliği ve uzlaşma kültürü müzakerelerin ana argümanlarını oluşturmuştur.

Mülakatlarda en çok vurgulanan hususlardan biri de iyi niyetli iletişim $(\% 89,8)$ konusudur. BG'nde görev alacak herkesin belirli bir seviyenin üzerinde ortak lisan olarak kullanılan İngilizce'ye hâkim olması gerektiği, aksi takdirde yanlış anlaşılmaların kaçınılmaz olacağı ifade edilmiştir.

Birlikte görev yapılan ülke personeli dışında yerel halk ile olan temaslarda da kültürel farkındalık ve iletişim konularının önemli olduğu vurgulanan mülakatlarda, bir katılımcının karşılaştığı uç bir örnek bu konunun önemini vurgulaması açısından çok önemlidir. Afganistan'da görev yapan katılımcı, askerî danışmanlık maksadıyla gittiği Afgan Tugayı'nda aracını park ederken kendisi ile hemen hemen aynı anda park yerine aracı ile gelen Afganlı bir subaydan önce aracını park etmiştir. Afganlı subay, yapılan hareketin kendi kültüründe affedilemeyecek bir hata olduğunu ve kendisine göre söz konusu hatayı yapanın mutlaka ağır şekilde cezalandırılması gerektiğini vurgulamıştır. Hatta daha da ileri giderek eğer bunu yapanın Türk subayı değil de başka bir ülkenin bir askerî olması halinde, o kişiyi bu davranışından dolayı orada öldürebileceğini yemin ederek ifade etmiştir. Söz konusu ifade, kültürel farklılığın ve sonucunun alabileceği en uç nokta olarak değerlendirilmiştir.

Mülakatlarda öne çıkan hususlardan biri de kültürel farklılıklardan kaynaklanan problemlerin etkilerinin azaltılmasının sağlanmasında; yabancı ülkelerde verilen eğitim ve uluslararası ortak tatbikatlara iştirak etmek, görev öncesi kültürlerarası farklılıkları ve bunların dikkate alınmasını vurgulayan eğitimler vermek $(\% 85,7)$ bu faaliyetlerden en öncelikli olanlar olarak öne çıkmıştır. Göreve gitmeden önce Ankara'da göreve yönelik verilen kurslarda, görev yapılacak ülke, ülkenin tarihi, şu anki duruma nasıl geldiği, yerel kültür ile göreve katılacak diğer ülkelerin kültürleri hakkında eğitimlerin verilmesi, henüz göreve katılmadan önce kültürel farkındalığın oluşturulmasına yardımcı olmaktadır. Benzer şekilde görev esnasında da verilen eğitimlerin söz konusu kültürel farkındalığı artırdığı ifade edilmiştir.

Bu bağlamda katılımcılardan birinin Kosova'da KFOR görevi esnasında kilit lider personel için düzenlenen eğitimde yaşadığı olay örnek olarak verilebilir. Eğitim kapsamında beş görev bölgesine ayrılan Kosova'daki tüm sorumluluk alanları gezilmiş ve bilgiler alınmıştır. Alman Tugayının sorumluluğunda olan bölgedeki eğitimler tamamlandığında, Alman mihmandarlar eşliğinde kültür amaçlı 
Çok Kültürlü İş Ortamlarında Entegrasyon Mekanizmaları:

gezdirilen Prizren şehir merkezine uzak bir mesafedeki eski bir manastırın tanıtımı sırasında, söz konusu manastırın Osmanlılar tarafından yıkıldığı, buradan sökülen taşların Prizren merkezindeki bir caminin inşasında kullanıldığı belirtilmiştir. Yapılan itiraz ile Osmanlının gittiği her yerde diğer kültürlere ve dinî inançlara saygı duyduğu, buradan sökülen taşlarla şehir merkezinde inşa edildiği iddia edilen caminin hemen 50 metre yakınında bir kilise bulunduğu, ama Osmanlının yakındaki kiliseyi yıkıp oradaki taşları kullanmak yerine, şehir merkezine uzaktaki bir manastırın taşlarını o günkü yol ve lojistik zorluklara rağmen taşıma zahmetine katlanarak bu camiyi inşa ettiğinin açıklanamayacağı belirtilmiş ve bilgiyi veren Alman subayına konuya yönelik ellerinde bilgi, belge olup olmadığı sorulmuştur. Sonrasında konu Alman Tugay Komutanına yapılan yazılı müracaatla, Osmanlının başka kültür ve dinî inançlara saygı duyduğuna ilişkin yabancı akademisyen ve yazarların çalışmalarına atıflar verilerek, söz konusu iddiaların takdim metinlerinden çıkartılması sağlanmıştır. Birlikte eğitim alınması sürecinde tanışıklığın verdiği güvene dayalı diyalog ve uzlaşma yöntemiyle çözülen bu yanlış anlama bir daha yaşanmamıştır.

Ayrıca, harekât alanında görev paylaşımı yapmak $(\% 79,5)$ suretiyle işbirliği ve koordinasyona ihtiyaçlarını ve olabilecek problemleri minimize etmek, birlikler arasındaki üst düzey koordinasyonu çok uluslu karargâh vasıtasıyla sağlamak konuları da diğer öne çıkan mekanizmalar olarak vurgulanmıştır. Bu bağlamda özellikle ilgili ülkenin sorumluluk alanında meydana gelen olayların vakit kaybedilmeksizin çok uluslu karargâha ve onun vasıtasıyla diğer karargâhlara iletilmesi ve söz konusu olayların BG'nün büyük bir sinerji yaratarak birlikte müdahalesi ile çözümlenebilmiştir.

Operasyonel bilgi akışını gerçek zamanlı ya da gerçek zamana yakın olarak sağlamak $(\% 83,6)$, iletişimi koordine ederek ülkelerin özellik arz eden konulardaki bilgi ve tecrübelerini paylaşmalarını $(\% 85,7)$ ve karşılıklı öğrenme süreçlerini hayata geçirmek faaliyetleri de bütünleştirme mekanizmaları içerisinde yer alabilecek önemli yaklaşımlar olarak ifade edilmiştir. Örneğin Türk Ordusu'nun terörle mücadeledeki 30 yılı aşkın tecrübesi, özellikle Afganistan gibi hayati tehlike altında görev icra edilmesi gereken bir harekât alanında çok faydalı olmuştur. Türk askerinin alan kontrolü görevleri esnasında patlamamış mühimmat ya da bomba olma ihtimali yüksek malzeme ile karşılaştığında, söz konusu mühimmatı serinkanlılıkla imha etmesi ve sonrasında da göreve devam etmesi 
diğer tüm ülkelerin takdirini kazanmıştır. Aynı durum ile karşılaşan diğer ülke askerlerinin derhal patlayıcı madde imha ekibini talep ettiği, patlamamış mühimmat ile karşılaşan birliğin harekât alanından çekilerek daha pasif görevlerde kullanıldığ1 görülmüştür. $\mathrm{Bu}$ nedenle Türk askerî, çeşitli vesileler ile terörle mücadelede kazandığı tecrübeleri diğer ülke askerlerine aktarmıştır.

Takım ruhunu ve işbirliğini sağlayacak liderlik anlayışına sahip personeli görevlendirmek $(\% 85,7)$, ülke birliklerinin karşılıklı olarak birbirlerini tanıması, etkileşimi ve güven tesisi için ortak eğitimler, kültürel ve sportif aktiviteler düzenlenmek $(\% 93,9)$ de kültürel farklılıklarla başa çıkmakta yararlanılabilinecek diğer entegrasyon mekanizmaları olarak sıralanmıştır. Bu bağlamda ülkelerin ulusal günlerinde düzenledikleri etkinliklere diğer BG unsurlarını davet etmeleri, mesai saatlerinde mevcut olmayan bir rahatllk içerisinde birbirlerini ve kültürlerini tanıma ve tanıtmaya vesile olduğu vurgulanmıştır. Özellikle de her firsatta birlikte çalışılan yabancı personeli Türk karargâhına davet ederek onlara Türk misafirperverliği ve kültürünü diğer Türk personelle olan ilişkilerini göstermelerinin; bunun yanında firsat buldukça diğer ülke personelinin millî ünitelerini ziyaret edip, onları ve kültürlerini daha yakından tanımaya çalışmanın ilişkilerde daha çabuk güven tesisi açısından yararlı olduğu ifade edilmiştir.

Ancak bazı katılımcılar; karşı tarafa saygı duyma, onları anlamaya çalışma, kendi kültürlerinden farklı olduklarını kabullenme, görevi ifa ederken çalışma arkadaşlarına yardım etme gibi kullandıkları entegrasyon mekanizmalarının işlerini kolaylaştırsa da iyiniyetli mesajlarını ulaştırmayı başaramadıkları yabancı personelin de olduğundan söz etmişlerdir. Bu kişilerin gösterilen bu tür iyi niyetli yaklaşımları anlamakta zorluk çektiklerini, karşılıksız yapılan iyilikler ve iyi niyet gösterilerinin altında mutlaka gizli bir ajanda olduğuna inandıklarını gözlemlemişlerdir. Bunun nedeni olarak da genellikle bireyselci tutum izleyen batılı kültürlerin doğal sonucu olarak kabul edilmiş, ancak yine de daha iyi ve farkl1 yöntemlerle onları da kazanmak için uğraş verildiği ifade edilmiştir.

Söz konusu kültürel entegrasyon mekanizmalarına ilave olarak çeşitli vesilelerle bir araya getirilen ülke askerlerinin birbirlerini tanıdıkça sahip olunan önyarg1 ve kalıp düşüncelerden kurtulmasını (Elron vd., 1999) sağlayarak $(\% 83,6)$, tüm ulusların eşit olduğu bilincini aşılamak ve çok uluslu gücün üst seviyede belirlenmiş ana amaca yöneltilmiş tek bir birlik haline dönüştürülmesini (Elron vd., 2003) sağlamak $(\% 89,8)$ da bütünleştirme mekanizmalarının etkili kullanımına olanak tanıyabilecektir. Bu bağlamda, mülakatlarda personel beraber çalıştığı diğer 
Çok Kültürlü İş Ortamlarında Entegrasyon Mekanizmaları:

ülke personelinde kendilerini en çok rahatsız eden uygulamalar olarak aşırı alkol tüketimi ve bu nedenle de bazı geceler oldukça fazla gürültü etmeleri nedeniyle çevreyi rahatsız etmeleri, görev aldıkları şubelerin ortak kullanımına sunulan görev araçlarını kendi şahsi malları gibi kullanmaları belirtilmiştir. Buna benzer problemleri tolere etmek için çok çabaladıklarını ve bu tür uygulamaları mazur gördüklerini ifade etmişlerdir. Temelde bu yaklaşımın altında yatan unsurların Türk askerî kültürünün sahip olduğu toplulukçu kültür, gruba bağl1lık ve kısmen dişil özellikler ile tam bir uyum içerisindedir.

Bu bağlamda katılımcılardan birisinin verdiği başka bir örnek de Türk askerî kültürünün kısmen dişil özelliğini teyit etmektedir. Konu, görev yaptığ 1 karargâhta yan birimde şube müdürü olarak görev yapan Alman kadın subayla ilgilidir. Bahse konu kadın subay cinsiyet değiştirmiş bir yarbaydır. Ortak icra edilen hiçbir faaliyette Alman subayının bu hassas özelliğini öne çıkarmadıklarını, herhangi bir imada bulunmadıklarını ve her zaman kendisine olduğu gibi davrandıklarını ifade eden katılımcı; kadın subayın her firsatta kendisine ülkesinde bile bu şekilde davranılmadığını, dışlanmamasından duyduğu mutluluğu dile getirdiğini ifade etmiştir. Normal şartlarda bu konuda kendisine hoşgörü ile yaklaşmasını en son umduğu ülke askerlerinin Türkiye'den olacağını varsaydığııı, ancak zamanla bu düşüncesinin anlamsız bir önyarg1 olduğunu anladığını söylemiştir. Kurulan bu diyalog ve gösterilen hoşgörü sayesinde Alman kadın subayın uzun yılları içeren uluslararası tecrübelerinden kaynaklanan birikimini en ince ayrıntısına kadar aktardığı vurgulanmıştır.

Verilen örnekler bağlamında Türk askerî personelinin, kendine has kültürünün sağlayacağı olumlu katkıları öne çıkarıp, işbirliğine zarar verebilecek yönlerini dikkatli bir şekilde kontrol edip belirlenen hedefe yönlendirerek, bütünleştirme mekanizmalarından optimum düzeyde yararlanabileceği düşünülmektedir. $\mathrm{Bu}$ konuya yönelik mülakatlarda verilen cevaplar $\% 89,8$ oranında entegrasyon mekanizmalarının önyargı ve kalıp düşüncelerden kurtulmuş, kendine has kural, norm, değer, davranış ve paylaşılan amaçları içeren hibrit bir kültür oluşturulmasına katkı sağlayabileceği yönündedir.

Katılımcıların birçoğu, yerel halk ile olan tüm irtibat ve diyaloglarda Türk askerinin UBG ile yerel halk arasında köprü rolü üstlenildiğini ve bunun nedenin ise görev yapılan ülkeler ile Türkiye arasındaki tarihi bağlardan kaynaklandığını 
vurgulamıştır. Söz konusu aracılık rolü, meydana gelen problemlerin ç̧özümünde büyük fayda sağlamıştır.

Mülakatlarda verilen cevaplar, Türk Askerî Kültürünün sahip olduğu yüksek güç mesafesi, yüksek belirsizlikten kaçınma, toplulukçu, kısmen dişil, kısa vadeye odaklı ve kısmen baskıcı tavır eğilimi gösteren özellikleriyle uyum içerisindedir. Benzer şekilde, mülakatlardan ve yazarın katılımcı gözlemleri ile elde ettiği veriler, değişik tarihlerde uluslararası BG görevlerinde bulunmuş personelin yazmış olduğu görev sonuç raporlarındaki veriler ile çeşitli medya organlarında değişik tarihlerde çıkan haberlerle birbirini destekler niteliklerdedir. Bu bağlamda Türk ulusal ve askerî kültürü, esnek bir yapı içerisinde;

- Kültürlerarası entegrasyon mekanizmalarını kullanarak,

- Diğer ülke kültürlerinin farklı olduğunu anlayıp kabul ederek,

- Kültürel farkl11ıkları tolere edip onlara saygı göstererek,

- Kendine has kural, norm, değer, davranış ve paylaşılan amaçları içeren hibrid bir kültür oluşturarak BG görevlerinde meydana gelebilecek problemlerin aşabilir ve böylece başarıya ulaşabilir.

\section{Sonuç ve Tartışma}

Dünyada ekonomik sınırların kalmadığı, teknolojik gelişmeler sonucu artan hızlı bilgi paylaşımı ve küreselleşme nedeniyle dünyanın herhangi bir coğrafi noktasında meydana gelen olayların dışında kalmanın mümkün olmadığ 1 günümüzde; nasıl ki çok uluslu şirket ve örgütler giderek artan bir ölçekte dünya çapında boy gösteriyorsa, icra edilen BG ve insani yardım operasyonlarında değişik ülke ordularının görev alması kaçınılmaz hale gelmiştir.

Birer modern örgüt olarak uluslararası BG'leri; insan kaynağının önemini anlamış ve örgütün başarısının o örgütü oluşturan her biri farklı kültürlerden gelen heterojen bireylerin örgüt amaç ve hedeflerini benimsemelerine ve bunun devamını sağlamalarına bağlı olmaktadır. Söz konusu BG görevlerinde yer alan çok değişik ülkelere mensup unsurların ortak belirlenmiş ortak amaç ve hedeflere yönlendirilebilmesi için en başta düşünülmesi gereken kavram kültürdür ve bu kavram beraberinde kültürlerarası farklılıklar ile birlikte göreceliği gündeme getirmektedir. Çünkü kültürlerarası farklılıklar, değişik kültürlerin etkisindeki bireylerin farklı düşünmesi, farklı kavraması, farklı değerlendirmesi ve sonuç olarak farklı davranmasına sebep olmaktadır. 
Çok Kültürlü İş Ortamlarında Entegrasyon Mekanizmaları:

Çok uluslu askerî kuvvetlerin bir araya getirilmesi konusunda en temel zorluk, kültürel farklılıklardan kaynaklanan problemlerin giderilmesi için gerekli adımların atılmasını gerektiren işbirliklerine ihtiyaç duyulmasıdır. Kültürel farklı1ıklar bağlamında ortaya çıkan çatışma ya da problemlerde yaratıcı davranmak ve aşırı keskin uçlar arasında denge kurmak önem arz etmektedir. Çünkü kültürel farklılıklar, operasyonun herhangi bir safhasında açık veya gizli bir şekilde çeşitli alanlarda gündeme gelebilirler. Söz konusu kültürel farklılıkların minimize edilmesi için henüz ne askerî ne de akademik dünyada icat edilmiş bir formül ya da reçete bulunmamaktadır.

Çeşitli ülke silahlı kuvvetlerinin katılımıyla icra edilen uluslararası işbirliği gerektiren operasyonlarda etkin ve etkili bir yönetim kültürü oluşturabilmek için mevcut koşullar ile entegrasyon mekanizmalarını dikkate alarak neler yapılması gerektiği konusunda; kendi ulusal kültürünü içerdiği farkl1lıklarla birlikte anlamanın yanında, diğer ülke kültürlerinin farklı olduğunu anlamanın, kabul etmenin ve bunlara duyarlı olmanın ön plana çıktığı görülmektedir. Bunun için özellikle görev öncesi dönemde, birlikte görev yapılacak ülkeler ile ev sahibi ülkenin kültürü hakkında kültürel farkındalığın sağlanmasına yardımcı olacak eğitimlerin verilmesine, yanlış bir şekilde edinilmiş ön yarg1 ve negatif düşüncelerden kurtulmak gerektiğine vurgu yapılabilir. Sonrasında, herhangi bir ulusal kültürün bir diğerinden daha iyi ya da daha kötü olmadığı bilinci ile kültürel farklılıkları tolere edecek ve onlara saygı gösterecek yaklaşımları içeren adımların atılması teşvik edilmelidir.

Kültürlerarası işbirliği için gerekli şartların oluşturulması ve farklılıkların entegrasyon mekanizmaları bağlamında bütünleştirilmesi ve yönetilmesi ile oluşturulacak kendine has kural, norm, değer, davranış ve paylaşılan amaçları içeren ve uzlaşılabilecek ortak değerler zemininde temellendirilmiş hibrit kültürün, UBG'nün ve bu göreve katkı sağlayan personelin başarılı olmasını sağlayacağ ifade edilebilir.

Gelecekte yapılacak çalışmalarda; bu çalışmada kullanılan nitel veri toplama yöntemlerine ilave olarak nicel veri toplama yöntemlerinin de kullanmasının, geçerlilik ve güvenilirlik konusunda daha güçlü ve genellenebilir bulgulara ulaşılabilme sürecinde yararlı olabileceği değerlendirilmektedir.

Teşekkür Notu: Bu çalışmaya değerli yorum ve eleştirileri ile katkıda bulunan Prof.Dr. A.Kadir Varoğlu ve Prof.Dr. Ünsal Sığrı'ya teşekkürlerimi sunarım. 


\section{Extended Summary}

The purpose of the study is to examine the intercultural integration mechanisms that can be used to be successful at international peacekeeping operations. Since the end of the Cold War, the budgets of many national militaries have been reduced considerably. Because they do not have enough resources available on their own, a lot of national militaries need to work together as international peacekeeping missions. International peacekeeping operations can always have the potential to create culturally-based problems in interactions among different nations who contribute to the mission. Because of the fact that it is impossible to prevent culture-based problems, it is necessary to develop a holistic approach to culture, cross-cultural relations, and their effects. In this study, a view of culture as a model for understanding other cultures with their diversities has been presented, and some cultural integration mechanisms have been suggested.

In this essay, qualitative data gathered via interviews with people who served in international peacekeeping operations (Kosovo, Bosnia-Herzegovina, Lebanon, and Afghanistan), author's participant observations, archive reviews including mission result reports, and media news. The interviews were conducted by the author of this article and took on average of 70 minutes each. They were taped, and deciphered. The deciphered writings were analyzed in Qualitative Data Analysis (QDA) Miner 4.0 software. The QDA Miner 4.0 program is designed to assist researchers in managing, coding and analyzing qualitative data.

The interviews focused mostly on intercultural integration mechanisms that can be used to be successful at international peacekeeping operations. The interviews consist of five questions, which are: 1 . Which type of cultural issues did you face during multinational military operations? What are the cultural integrating mechanisms and methods did you use to facilitate challenges and be successful in multinational military operations? 3. Did you make use of negotiation \& collaboration to facilitate challenges? 4. Did your methods work? How efficient were they? How long did it take to get result? Could you please give some examples? 5. Did your methods lead to create a prejudice and stereotype free "hybrid culture", which has its own values, norms, behaviors and goals? The answers given to the questions show that most of the participants are aware of the cultural differences and diversities. The differences emphasized by the participants are; value priorities, goal preferences, the language factor, disparities in attributions 
Çok Kültürlü İş Ortamlarında Entegrasyon Mekanizmaları:

about causes and intentions of behaviors, communication gaps, stereotyping, and prejudice. There is also a common understanding of need for a mechanism to manage those differences to prevent conflicts, thus enabling the separate forces to be part of an integrated structure. Some of the cultural integrating mechanisms emphasized are: communication, good manner and good will, personal skills, internal division of labor, joint training and exercises prior to mission, crosscultural training, information flows and sharing of knowledge, exchange of experiences, deliberate cohesion building activities during mission, goal-oriented team effort, and flexibility.

The qualitative data gathered via interviews were all cross-checked with author's participant observations, archive reviews including mission result reports, and media news. The results of the perceptions of the participants on the cultural integrating mechanisms generally supported the previous studies of determining Turkish culture with high power distance, strong uncertainty avoidance, slightly feminine and collective with regard to Hofstede's cultural dimensions; short-term oriented and slightly restraint with regard to Bond and Inglehart's work respectively.

As it is well known, culture differs in each nation. The differences may be simple or complex, they may be explicit or implicit. Whatever the differences are, one thing is taken for granted; there is no "right" formula for minimizing these cultural differences. But an awareness of their existence is an essential element for meeting the challenges they pose. When national militaries possessing diverse cultural backgrounds must work together, differences among them can become profound drawbacks to mission success. A model has been suggested to clear these impediments on the way to success, which is as follows. It is obvious that besides understanding his/her own culture with its diversities, one needs to understand and accept that other cultures are different. This is the first and important step in order to establish efficient and effective cultural management during the international peacekeeping operations- with the participation of various nations, which requires tremendous amount of international cooperation. With the consciousness of that no culture is better or worse than one another, one needs to follow approaches that tolerating cultural differences and showing respect for the other cultures. In this respect, we emphasize a hybrid culture, established by the intercultural cooperation 
and intercultural integration mechanisms, can help international peacekeeping force to be successful.

\section{Kaynakça}

\section{Kitaplar}

Adler, N.J. (1991). International dimensions of organizational behavior. Boston, Massachusetts: PWS-KENT Publishing Company.

Elron, E., Halevy, N., Ben-Ari, E. ve Shamir, B. (2003). Cooperation and coordination across cultures in the peacekeeping forces: Individual and organizational integrating mechanisms. İçinde T.W. Britt ve A.B. Adler (Ed.), The Psychology of The Peacekeeper: Lessons from The Field (ss. 261-282). Westport, CT: Praeger Publishers.

Hofstede, G.J., Pedersen, P.B. ve Hofstede, G. (2002). Exploring culture: Exercises, stories and synthetic cultures. Maine: Intercultural Press.

Hofstede, G., Hofstede, G.J. ve Minkov, M. (2010). Cultures and organizations: Software of the mind. New York: McGraw Hill.

Klein, H., Pongonis, A. ve Klein, G. (2000). Cultural barriers to multinational C2 decision making, 2000 command and control research and technology symposium. Dayton, $\mathrm{OH}$ : Wright State University.

Sargut, S. (2010). Kültürlerarası farklılaşma ve yönetim, 3.Baskı. Ankara: İmge Kitapevi.

Selmeski, B.R. (2007). Military cross-cultural competence: Core concepts and individual development. Centre for Security, Armed Forces \& Society, Royal Military College of Canada, AFCLC Contract Report 2007-01.

Sığrı, Ü. (2018). Nitel Araştırma Yöntemleri. İstanbul: Beta Yayınevi.

Solomon, C.M. ve Schell, M.S. (2009). Managing across cultures: The seven keys to doing business with a global mindset. New York: McGraw-Hill.

Trompenaars, F. ve Hampden-Turner, C. (1998). Riding the waves of culture, understanding cultural diversity in business. London: Nicholas Brealey Publishing. 
Çok Kültürlü İş Ortamlarında Entegrasyon Mekanizmaları:

Uluslararası Barış Güçleri Üzerine Nitel Bir Araştırma

Van Driel, M. (2011). Overlap between leadership competencies and crosscultural competencies. Defense Equal Opportunity Management Institute Directorate of Research, Technical Report No. 05-11.

\section{Makaleler}

Adler, N.J. (1983). Cross-cultural management: Issues to be faced. International Studies of Man, XIII(1-2), 7-45.

Adler, N.J. ve Jelinek, M. (1986). Is organization culture culture bound? Human Resource Management, 25(1), 73-90.

Allen, S.H. ve Yuen, A.T. (2014). The politics of peacekeeping: UN Security Council oversight across peacekeeping missions. International Studies Quarterly, 58, 621-632.

Altay, H. (2004). Güç mesafesi, erkeklik-dişilik ve belirsizlikten kaçınma özellikleri ile başarı arasındaki ilişkilerin incelenmesine yönelik bir araştırma. Süleyman Demirel Üniversitesi Íktisadi ve İdari Bilimler Fakültesi Dergisi, 9(1), 301-321.

Duffey, T. (2000). Cultural issues in contemporary peacekeeping. International Peacekeeping, 7(1), 142-168.

Elron, E., Shamir, B. ve Ben-Ari, E. (1999). Why Don't they fight each other? Cultural diversity and operational unity in multinational forces. Armed Forces \& Society, 26(1), 73-98.

Joplin, J.R.W. ve Daus, C.S. (1997). Challenges of leading a diverse workplace. Academy of Management Executive, 11(3), 32-47.

Leca, I. ve Vrânceanu, C.A. (2014). Multicultural teams: Moving from diversity to inclusion. Cross-Cultural Management Journal, 16 (2), 361-368.

Pouligny, B. (1999). Peacekeepers and local social actors: The need for dynamic, cross-cultural analysis. Global Governance, 5, 403-424.

Rubinstein, R.A. (1993). Cultural aspects of peacekeeping: Notes on the substance of symbols. Journal of International Studies, 22(3), 547562.

Sığrı, Ü. (2006). Türk askerlik kültürünün kültürel farklılaşma boyutları ve yönetim kültürü kapsamında değerlendirilmesi. KHO Savunma Bilimleri Dergisi, 5(2), 53-73. 
Sığrı, Ü. ve Topçu, M.K. (2012). Barış gücü operasyonlarında kullanılan kültürleraras1 bütünleştirme yöntemlerinin kültürel boyutlar bağlamında incelenmesi: UNIFIL örneği. Ankara Üniversitesi SBF Dergisi, 67(1), 205-235.

Smith, P.B., Trompenaars, F. ve Dugan, S. (1995). The rotter locus of control scale in 43 countries: A test of cultural relativity. International Journal of Psychology, 30(3), 377-400.

Soeters, J., Van den Berg, C.E., Varoğlu, A.K. ve Sığrı, Ü. (2006). Barış gücü operasyonlarında Türkiye Hollanda buluşması. Uluslararası İlişkiler, 3(11), 71-102.

Soeters, J., Van den Berg, C.E., Varoğlu, A.K. ve Sığr1, Ü. (2007). Accepting death in the military: A Turkish-Dutch comparison. International Journal of Intercultural Relations, 31, 299-315.

Soeters, J. ve Tresch, T.S. (2010). Towards cultural integration in multinational peace operations. Defence Studies, 10(1-2), 272-287.

Varoğlu, A.K. ve Bıçaksız, A. (2005). Volunteering for risk: The culture of the Turkish Armed Forces. Armed Forces \& Society, 31(4), 583-598. 